\title{
How students perceive medical competences: a cross-cultural study between the Medical Course in Portugal and African Portuguese Speaking Countries
}

Joselina Barbosa ${ }^{1 *}$, Milton Severo ${ }^{1,2+}$, Mário Fresta ${ }^{3+}$, Mamudo Ismail $^{4+}$, Maria Amélia Ferreira ${ }^{1,5+}$ and Henrique Barros ${ }^{2,6+}$

\begin{abstract}
Background: A global effort has been made in the last years to establish a set of core competences that define the essential professional competence of a physician. Regardless of the environment, culture or medical education conditions, a set of core competences is required for medical practice worldwide. Evaluation of educational program is always needed to assure the best training for medical students and ultimately best care for patients. The aim of this study was to determine in what extent medical students in Portugal and Portuguese speaking African countries, felt they have acquired the core competences to start their clinical practice. For this reason, it was created a measurement tool to evaluate self-perceived competences, in different domains, across Portuguese and Portuguese-speaking African medical schools.
\end{abstract}

Methods: The information was collected through a questionnaire that defines the knowledge, attitudes and skills that future doctors should acquire. The Cronbach's Alpha and Principal Components Analysis (PCA) were used to evaluate the reliability of the questionnaire. In order to remove possible confounding effect, individual scores were standardized by country.

Results: The order of the domain's scores was similar between countries. After standardization, Personal Attitudes and Professional Behavior showed median scores above the country global median and Knowledge alone showed median score below the country global median. In Portugal, Clinical Skills showed score below the global median. In Angola, Clinical Skills and General Skills showed a similar result. There were only significant differences between countries in Personal Attitudes $(p<0.001)$ and Professional Behavior $(p=0.043)$.

Conclusions: The reliability of the instrument in Portuguese and Portuguese-speaking African medical schools was confirmed. Students have perceived their level of competence in personal attitudes in a high level and in opposite, knowledge and clinical skills with some weaknesses.

\section{Background}

During the last years a global effort has been made to define the minimum essential requirements and core competences that all medical graduates worldwide must have to be good physicians [1-5]. These competences comprise not just a set of general knowledge but also a set of clinical

\footnotetext{
* Correspondence: joselina@med.up.pt

+ Contributed equally

${ }^{1}$ Center for Medical Education, Faculty of Medicine, University of Porto, (Al.

Prof. Hernâni Monteiro), Porto, (4200-319), Portugal
}

Full list of author information is available at the end of the article skills and professional attitudes necessary to efficiently perform the medical practice [6]. Medicine is a global profession and medical competences, research and education have crossed national borders. A set of core competences required for medical practice throughout the world have been defined [1-5]. This concept is linked to the European Credit Transfer System (ECTS) and its impact on a global comparability in medical education. In Europe, the quality assurance frameworks and the portability of qualifications follow the directives of Bologna Process [7]. African

\section{Biomed Central}


Universities and its Medical Schools, supported by internal and external organizations, are trying to cope with this paradigm, changing their degree and qualification systems within European reforms [8-11]. Despite objective difficulties, such as lack of resources and properly delineated quality parameters to ensure quality university education [12], Medical Schools are being set up in many universities on the model of European reforms and offer the opportunity to change the current isolation and limited human resources [13].

A strict evaluation of the curriculum and educational reform are always needed to make sure that the best is done for medical students and ultimately for patients [14]. However, there is little or none information about how students of African medical schools evaluate their core competences. Against this background, the objectives of this study were to (i) create a measurement tool to evaluate self-perceived competences in different domains across Portuguese and Portuguese-speaking African medical schools and (ii) determine in what extent medical students in Portuguese and Portuguesespeaking African countries, felt they have acquired the core competences to start their clinical practice.

\section{Methods}

In order to develop this research we have selected, in the African Portuguese-speaking countries: the Faculty of Medicine of the University Agostinho Neto (FMUAN), Angola and the Faculty of Medicine of the University Eduardo Mondlane (FMUEM), Mozambique with traditional curricula according to the current curricular reform set up with new directives. These are Institutions in a Global Program in Educational Development. In Angola, the medical school has a curriculum reform in progress since 2002 [10,11,15-17] and in Mozambique and Angola a joint project entitled "A NAME for Health - A Network Approach in Medical Education for the Pursuit of Quality of Higher Education Institutions and Health Systems" is under development since 2008 and it also focuses competences assessment.

All students attending the final year (6th year) of Medicine Course at FMUP - Portugal, FMUAN - Angola and FMUEM - Mozambique were invited to participate in a cross-sectional study. Among the 398 eligible students, 76 (77.6\%) of Angola, 66 (67.3\%) of Mozambique and 157 (77.8\%) of Portugal, have participated in this study.

An evaluation scale of acquisition of core competences was designed based on "The Medical Graduate in Portugal" [18]. This document defined 112 competences combined in five domains (Knowledge, Professional Attitudes and Behavior, Clinical Skills and Practical Procedures, Communication Skills and General Skills).

All items followed a Likert scale ranging from 0 to 6 , where: 0 - has not acquired any competence, 1 - has acquired the minimum competences... 6 - has acquired the maximum competences.

Principal Components Analysis (PCA) was used to evaluate the dimensionality of the questionnaire items and Direct Oblimin rotation was applied to simplify the factor loadings structure. Given the large number of items comprising the questionnaire, the PCA was performed by domain and not by the total items. The Scree Plot criterion [19] was used to determine the number of components. It was considered that items with absolute factor loadings of 0.35 or greater are interpreted as having a meaningful part on the whole domain.

The PCA was performed within country to observe if factor loadings structure was different by country. The internal consistency was assessed using Cronbach's Alpha [20].

The score of each domain was obtained by averaging the corresponding items divided by 6 and multiplied by 100 (the score ranged 0 to 100). The highest values scores represent the higher levels of competence.

The scoring and interpretation of the students' level of competence was based on medians.

To remove possible confounding effect by a particular country, all individual scores were standardized. The standardization was performed subtracting the country global median from each individual score and then dividing the difference by the country inter-quartile range. This calculation will enable to evaluate if competences follow the same pattern in all countries. That is, the domains with higher and lower scores were, respectively, higher and lower scores in all countries.

The Friedman test was used to compare the domain's scores in each country. Multiple comparisons were also carried out using the Wilcoxon test by adjusting the level of significance according to the Bonferroni correction for multiple comparisons.

The Kruskal Wallis test was used to compare the scores of each domain by countries. The Spearman correlation was used to evaluate the association between countries.

All statistics analyses were performed with the Predictive Analytics Software version 18.0 (PASW Statistics Software). The significance level was set at 0.05 .

The ethical principles to this research followed the guidelines approved by FMUP, FMUAN and FMUEN.

\section{Results}

\section{Participants Characteristics}

In Angola, Mozambique and Portugal 15.8\%, 60.6\% and $91.7 \%$ of the students were aged less than or equal to 25 years old, respectively. Regarding the distribution by gender, in Angola, Mozambique and Portugal, 55.3\%, $49.1 \%$ and $71.3 \%$ of the students were female, respectively (Table 1). 
Table 1 Characteristics of students enrolled in the 6th year of the Courses of Medicine by country

\begin{tabular}{cccc}
\hline & \multicolumn{3}{c}{ Country } \\
\hline & Angola & Mozambique & Portugal \\
\hline Age & N (\%) & N (\%) & N (\%) \\
\hline _25 & $12(15.8)$ & $40(60.6)$ & $144(91.7)$ \\
]25-30] & $32(42.1)$ & $20(30.3)$ & $12(7.6)$ \\
]30-61] & $32(42.1)$ & $6(9.1)$ & $1(0.6)$ \\
Gender & & & \\
Female & $42(55.3)$ & $27(49.1)$ & $112(71.3)$ \\
Male & $34(44.7)$ & $28(50.9)$ & $45(28.7)$ \\
\hline
\end{tabular}

\section{Reliability of the Questionnaire Knowledge}

The Scree Plot of the original scale "Knowledge" suggested the existence of one component to Angola explaining $44.4 \%$ of the variance; one component to Mozambique explaining $49.0 \%$ of the variance; and one component to Portugal explaining $48.7 \%$ of the variance. The PCA has indentified in all medical schools the same domain designated Knowledge (Cronbach's Alpha = 0.962) (Table 2).

\section{Professional Attitudes and Behavior}

The Scree Plot of the original scale "Professional Attitudes and Behavior" suggested the existence of two components to Angola explaining 50.4\% of the variance (the first explaining $40.0 \%$ and the second explaining $14.5 \%)$; one component to Mozambique explaining $47.8 \%$ of the variance; and one component to Portugal, explaining $59.2 \%$ of the variance.

A PCA followed by direct oblimin rotation was carried out in Angola. The sub-scales "Professional Relationships" and "Relation with the Society and with the System of Health Care" were joined in one component designated Professional Behavior (Cronbach's Alpha = 0.917). The sub-scale "Personal Attributes" was split in two components, so it was decided to considerate this domain Personal Attributes (Cronbach's Alpha $=0.915$ ) with only the items that load in second component. Therefore, not being considered in the analysis the four items that load in first component ("Recognize my own limitations", Personal commitment in the defense of professional values", "Take responsibility for my learning", "Conduct a self-reflection").

Based on Angola PCA structure, the items were separated in two domains for all medical schools (Table 2).

\section{Clinical Skills and Practical Procedures}

The Scree Plot of the original scale "Clinical Skills and Practical Procedures" suggested the existence of one component to Angola explaining $61.8 \%$ of the variance; one component to Mozambique explaining $59.0 \%$ of the variance; and one component to Portugal explaining $56.2 \%$ of the variance. The PCA has indentified in all medical schools the same domain designated Clinical Skills (Cronbach's Alpha $=0.970)($ Table 2).

\section{Communication Skills}

The Scree Plot of the original scale "Communication Skills" suggested the existence of one component to Angola explaining $66.3 \%$ of the variance; one component to Mozambique explaining $59.5 \%$ of the variance; and one component to Portugal explaining $66.7 \%$ of the variance. The PCA has indentified in all medical schools the same domain designated Communication Skills $($ Cronbach's Alpha $=0.970)($ Table 2$)$.

\section{General Skills}

The Scree Plot of the original scale "General Skills" suggested the existence of one component to Angola explaining $62.3 \%$ of the variance; one component to Mozambique explaining $64.6 \%$ of the variance; and one component to Portugal explaining $60.4 \%$ of the variance. The PCA has indentified in all medical schools the same domain designated General Skills (Cronbach's Alpha = 0.955) (Table 2).

\section{Core Competences}

The scores in all domains and in all medical schools ranged from 66.0 to 96.3 points. The domains with higher scores in Angola and Mozambique were Personal

Table 2 Principal Component Analysis

\begin{tabular}{|c|c|c|c|c|c|c|c|c|c|}
\hline \multirow[t]{2}{*}{ Domains } & \multicolumn{3}{|c|}{ Angola } & \multicolumn{3}{|c|}{ Mozambique } & \multicolumn{3}{|c|}{ Portugal } \\
\hline & $\begin{array}{l}\text { Variance } \\
\text { Explained }\end{array}$ & $\begin{array}{l}\text { Minimum } \\
\text { Factor } \\
\text { Loadings }\end{array}$ & $\begin{array}{l}\text { Maximum } \\
\text { Factor } \\
\text { Loadings }\end{array}$ & $\begin{array}{l}\text { Variance } \\
\text { Explained }\end{array}$ & $\begin{array}{c}\text { Minimum } \\
\text { Factor } \\
\text { Loadings }\end{array}$ & $\begin{array}{l}\text { Maximum } \\
\text { Factor } \\
\text { Loadings }\end{array}$ & $\begin{array}{l}\text { Variance } \\
\text { Explained }\end{array}$ & $\begin{array}{l}\text { Minimum } \\
\text { Factor } \\
\text { Loadings }\end{array}$ & $\begin{array}{l}\text { Maximum } \\
\text { Factor } \\
\text { Loadings }\end{array}$ \\
\hline Knowledge & 44.4 & 0.440 & 0.773 & 49.0 & 0.571 & 0.826 & 48.7 & 0.516 & 0.780 \\
\hline $\begin{array}{l}\text { Personal } \\
\text { Attitudes }\end{array}$ & 40.0 & 0.462 & 0.860 & 47.8 & 0.452 & 0.849 & 59.2 & 0.589 & 0.855 \\
\hline $\begin{array}{l}\text { Professional } \\
\text { Behavior }\end{array}$ & 14.5 & 0.388 & 0.901 & & & & & & \\
\hline Clinical Skills & 61.8 & 0.662 & 0.898 & 59.0 & 0.536 & 0.873 & 56.2 & 0.586 & 0.844 \\
\hline $\begin{array}{l}\text { Communication } \\
\text { Skills }\end{array}$ & 66.3 & 0.539 & 0.897 & 59.5 & 0.562 & 0.871 & 66.7 & 0.654 & 0.897 \\
\hline General Skills & 62.3 & 0.575 & 0.900 & 64.6 & 0.664 & 0.895 & 60.4 & 0.531 & 0.884 \\
\hline
\end{tabular}


Attitudes (94.4 and 96.3 points, respectively) and Professional Behavior (94.4 and 96.3 points, respectively). In Portugal it was Personal Attitudes (90.7 points). The domains with lower scores in Angola were Clinical Skills (78.7 points) and Knowledge (79.3 points). In Mozambique it was Knowledge (83.3 points), Clinical Skills (86.7 points) and General Skills (88.7). In Portugal it was General Skills (74.5 points) and Communication Skills (76.3 points). Mozambique medical students showed higher scores in all competences than medical students from Angola and Portugal; those from Angola presented a higher level of competences than their Portuguese colleagues (Figure 1).

There were significant correlations between the domain's scores assigned by each country (Portugal vs. Angola $r=0.986$; Portugal vs. Mozambique $r=0.928$; Angola vs. Mozambique $r=0.941$ ).

To remove possible confounding effects by country, all individual scores were standardized. After standardization, significant differences between countries were only detected in the competences: Personal Attitudes ( $\mathrm{p}<$ $0.001)$ and Professional Behavior $(\mathrm{p}=0.043)$. Portugal showed significantly higher scores than Mozambique in Personal Attitudes (0.66 vs. 0.32), whereas Angola showed higher scores than Portugal and Mozambique (0.51 vs. 0.32 ).
In all countries, Personal Attitudes (Portugal $=0.66$; Angola $=0.51 ;$ Mozambique $=0.32$ ) and Professional Behavior (Portugal $=0.32$; Angola $=0.51$; Mozambique $=0.32$ ) showed median scores above the country global median and Knowledge alone (Portugal = -0.24; Angola $=-0.33$; Mozambique $=-0.42)$ showed median score below the country global median.

In Portugal, Clinical Skills (Median $=-0.49$ ) showed a score below the global median. In Angola, Clinical Skills $($ Median $=-0.37)$ and General Skills $($ Median $=-0.27)$ showed a similar result (Table 3).

\section{Discussion}

At the end of graduation, medical students must possess the professional competences that are necessary to meet their individual and collective responsibilities to society. Acquired competences are definitely a central indicator for the quality of a curriculum. Regardless of the environment, culture or medical education conditions, a set of core competences are required for medical practice worldwide [1-5].

\section{How domains are perceived by medical students}

In this sample, four original domains showed good homogeneity (strong first factor) and high internal consistency (minimum Alpha $=0.92)$ and only one domain

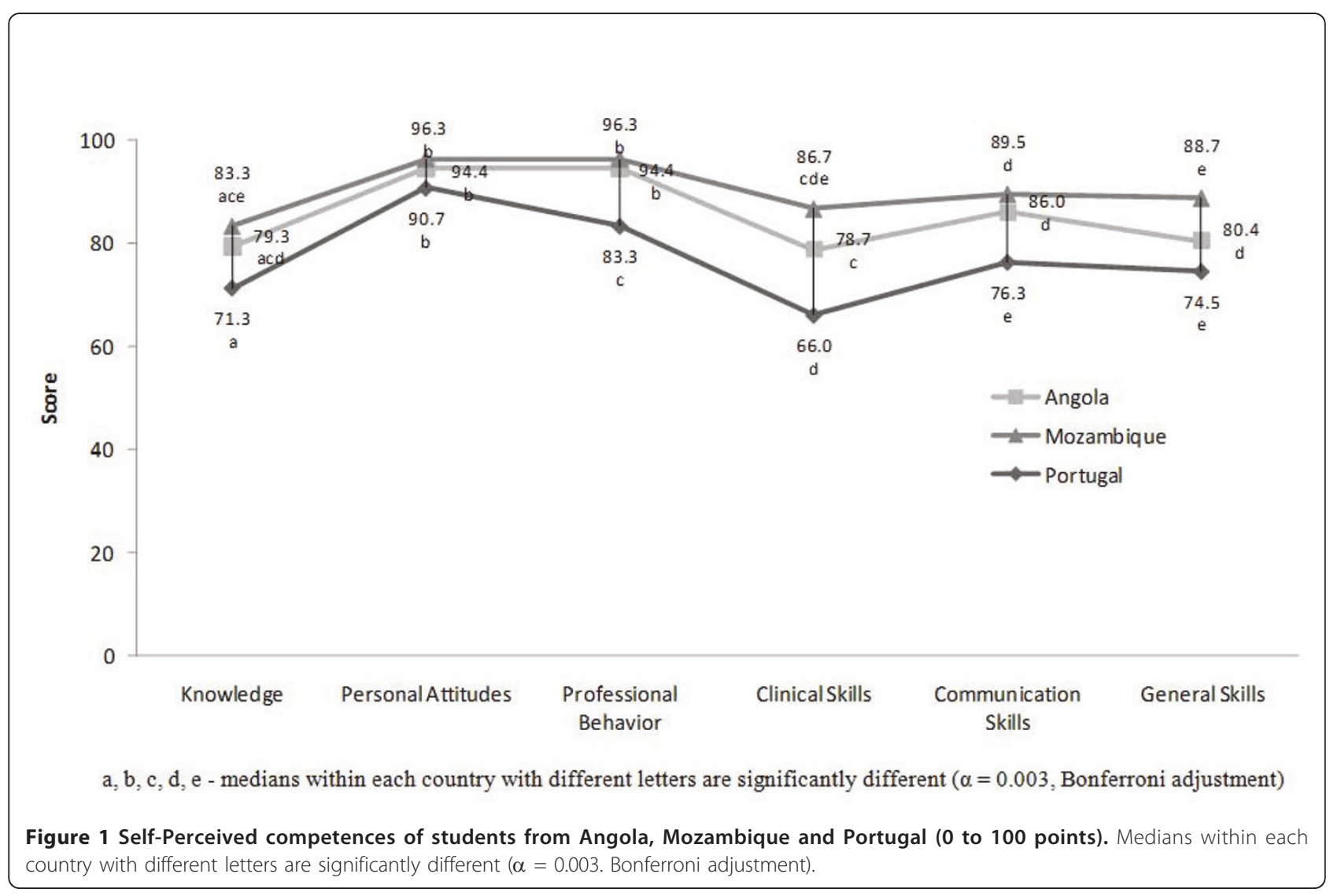


Table 3 Distribution of domains by country (standardized values)

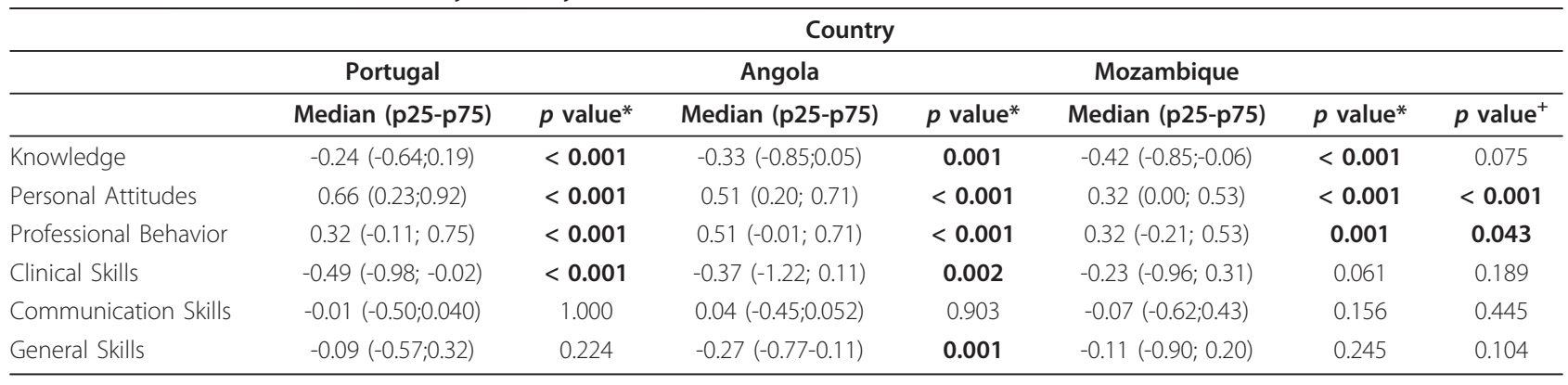

* Median significantly different from zero.

+ Difference of medians between countries.

(Professional Attitudes and Behavior) showed the existence of two sub-domains. Furthermore, these items and competences showed content validity based a previous study [18]. So, our scale evaluates competences combined in six domains: Knowledge, Personal Attitudes, Professional Behavior, Clinical Skills, Communication Skills and General Skills.

Overall, in all studied countries, medical students showed that they felt truly competent in the core set of medical competences. All students tended to give high scores to all domains.

Students from Mozambique showed higher scores than their colleagues from Angola and these showed higher scores than Portuguese medical students. This may show that the self-perceived competences are confounded by contextual differences. This outcome could be explained by different self confidence levels attributed to the different learning environments or countries [21]. Other factors can also contribute towards the acquisition of competences and its perception on students. These found factors and differences can be explained by possible differences in teaching and background of students among countries which will affect perceived competences. Correlation competences between countries showed similar patterns scores; the domains with higher and lower scores had, respectively, higher and lower scores in all countries. So, it was decided to standardize the individual scores by country to remove possible confounding effects. After standardization it was possible to understand the real differences. The domains Personal Attitudes and Professional Behavior were found to have higher scores of self-perceived competences in all countries. This means that medical students felt more competent in their attitudes. The domain Communication Skills was evaluated in the median. A study about perceptions of educational development during the first year of post graduation for medical students in the UK showed that when they were asked which competences they experienced a bigger development the students emphasized the skills of communication, teamwork and outcomes related to personal development [22]. These results may be due to the fact that students take these competences as inherent to a future physician and therefore assume that they must be acquired. It is noticed that there are also areas where the assessment is difficult. Methods and techniques of assessment in medical schools are based, is most cases, on written work and a discussion rather than a direct observation of student-patient interactions [23]. This could influence students in their perception based on their grades.

Instead, Knowledge in all countries and Clinical Skills in Portugal and Angola showed lower scores. Many studies have addressed their experiences as new doctors when they enter the world of clinical practice. It has been demonstrated that new graduate doctors often mention problems associated with their own shortcomings in knowledge, skills and general competences [24].

The low values assigned to the acquisition of competences in Clinical Skills may be due with the students' fear of making mistakes or the limited opportunities for practice during under graduation. This aspect emphasizes the importance of clinical training throughout the medical education process. Still, the area of therapeutics, included in Clinical Skills, causes a great discomfort to students of Medicine. At the end of the degree and prior to take on the responsibility for prescribing, students do not feel prepared and they are aware that prescribing has the power to bring great benefits but also the risk of causing major damage [25]. Most students will require not only knowledge of existing drugs but also a strong knowledge of the principles of pharmacotherapy sustained by a scientific knowledge of drug action.

Although Personal Attitudes and Professional Behavior were been the domains with higher scores in all countries, these were the only domains in which significant differences among countries were demonstrated. Portugal achieved a higher level of competences in Personal Attitudes which was significantly different from Mozambique. In Angola there was a higher level of competences in 
Professional Behavior, significantly different from Portugal and Mozambique.

\section{Limitations of the study}

Albeit the relevance of the results obtained, this work shows limitations which are due to different factors that have to be considered for this discussion: (i) It must be pointed out that we obtained the samples students of different countries at different times, within educational contexts where differences in teaching patterns and backgrounds of students are likely to affect perceived competences. However, we tried to remove these confounding differences in perceived competences through the standardization. (ii) The method of self-assessment is neither objective nor free from beliefs and values that individuals hold about themselves. Self-evaluation instruments are more adequate to analyze work practices and promote reflection on performance [26]. However, they do not help at the same extent to judge the accuracy of the individual's evaluation. (iii) Despite knowing what a student think and what he is capable to do, we cannot provide data for the real performance.

\section{Conclusions}

Self-assessment allows medical students not only to build self-reflection skills and to identify areas of improvement, but it also helps in decision-making and, therefore, it is an important part of medical education, towards patient care. Self-assessment is also a valuable tool to identify potential problem areas where either the objectives or teaching require adjustments [27].

This study provides some useful insights into the preparedness of students completing undergraduate medical education. Students had considered themselves with high level in all core competences, although with different levels of self-perceived competences. While the scores for the domains were different, the order of the scores was similar between countries. This result confirms the comparability among countries. However, to fully evaluate the quality of acquisition of medical competences, in terms to proceed towards accreditation process and consequently to provide solid background for comparability between medical graduates of different countries, it is necessary to take into consideration contextual and developmental differences.

The students have perceived their level of competence in personal attitudes in a high level, and in opposite, knowledge and clinical skills with some weaknesses. There is a need to evaluate attitudes and the conduct of medical students with direct measures.

The dynamics of changes in medical education is determined by multiple factors that need to be discussed and articulated as a whole. The evaluation of medical competence is a complex task, and no single evaluation tool can effectively assess the physician's knowledge, skills and attitudes [28]. Ongoing evaluations in student competences should be undertaken as well new strategies for learning should be implemented in anticipation of changes in environment and to create opportunities for acquisition of medical competences. There is a need for further research to explore how medical competence is best assessed; be it in written formats, such as case studies, self-evaluation or another format, such as observing student's performance.

Two aspects have to be followed in further researches: (i) a follow-up of postgraduates is important to obtain their perceptions on professional performance, as the change in the clinical context allows a broader view and more accurate evaluation of medical competences and (ii) the present study could offer baseline data for the global comparability in medical education in Portuguese-speaking countries and then provide the generalisability of the study.

\section{Acknowledgements}

Authors thank the students of FMUAN/FMUEM/FMUP, the faculties of FMUAN and FMUEM, and Students Association of FMUAN/FMUEM/FMUP. Professors Cristóvão Simões and Pedro Magalhães (FMUAN) and Professor Vitória Branco Neves (FMUEM) were of great support for the implementation of the questionnaire.

This work was performed under the financial support of the Portuguese Institute for Support to Development (IPAD) under the Project "Structuring Program of Quality and Excellence of Medical Education/Training in FMUAN: Action for the Promotion of Health of Populations in Angola" 2007 and the European Commission and the Calouste Gulbenkian Foundation under Project EDULINK "A NAME for Health - A Network Approach in Medical Education for the Pursuit of Quality of Higher Education Institutions and Health Systems" (Grant contract number: 9-ACPRPR-18\#29).

Syed Ali, Phd (National Center for Toxicological Research, Jefferson, USA) for revising the English language.

\section{Author details}

${ }^{1}$ Center for Medical Education, Faculty of Medicine, University of Porto, (Al. Prof. Hernâni Monteiro), Porto, (4200-319), Portugal. '2Department of Hygiene and Epidemiology, Faculty of Medicine, University of Porto, (Al. Prof. Hernâni Monteiro), Porto, (4200-319), Portugal. ${ }^{3}$ Center for Advanced Studies in Medical Education, Faculty of Medicine, University Agostinho Neto, (Av. Hoji ya Henda), Luanda, (116), Angola. ${ }^{4}$ Faculty of Medicine, University Eduardo Mondlane, (Av. Salvador Allende), Maputo, (257), Mozambique. ${ }^{5}$ Institute of Anatomy, Faculty of Medicine, University of Porto, (Al. Prof. Hernâni Monteiro), Porto, (4200-319), Portugal. Institute of Public Health, University of Porto, (Rua das Taipas), Porto (4050-600), Portugal.

\section{Authors' contributions}

JB designed the study, carried out the design research, performed the statistical analysis and drafted the manuscript. MS participated in study design, helped in statistical analysis and helped to draft the manuscript. MF contributed with technical support and helped to draft the manuscript. MI contributed with technical support and helped to draft the manuscript. MAF conceived of the study, coordinated the research and made a critical review of the manuscript. HB made a critical review of the manuscript and helped to draft the final approval of the version to be published. All authors read and approved the final manuscript.

\section{Authors' Information}

$\mathrm{JB}$ is researcher at the Faculty of Medicine of the University of Porto, graduate in Mathematics Applied to Technology. She attends the Master Course in Public Health. MS is researcher at the Faculty of Medicine of the 
University of Porto and Public Health Institute of the University of Porto, graduate in Mathematics Applied to Computation. He attends the PhD Course of Public Health. MF is Professor of Physiology and Director of the Center for Advanced Studies in Medical Education at the Faculty of Medicine of the University Agostinho Neto, Luanda, Angola. MI is Professor of Pathology and Director of the Faculty of Medicine of the University Eduardo Mondlane, Maputo, Mozambique. MAF is Full Professor and Director of the Center for Medical Education at the Faculty of Medicine of the University of Porto. HB is Professor of Hygiene and Epidemiology and Director of the Department of Hygiene and Epidemiology at the Faculty of Medicine of the University of Porto. He's also Director of the Institute of Public Health of the University of Porto and Coordinator of the National Commission for HIV AIDS.

\section{Competing interests}

The authors declare that they have no competing interests.

Received: 28 September 2010 Accepted: 25 May 2011

Published: 25 May 2011

\section{References}

1. Batalden P, Leach D, Swing S, Dreyfus H, Dreyfus S: General competencies and accreditation in graduate medical education. Health Affairs 2002, 21:103.

2. Frank J, Jabbour M, Tugwell P, Boyd D, Labrosse J, MacFadyen J: Skills for the new millennium: report of the societal needs working group, CanMEDS 2000 Project. Annals of the Royal College of Physicians Surgeons of Canada 1996, 29:206-216.

3. General Medical Council. Tomorrow's doctors: recommendations on undergraduate medical education: General Medical Council London; 1993.

4. Neufeld V, Maudsley R, Pickering R, Turnbull JM, Weston WW, Brown MG, Simpson JC: Educating future physicians for Ontario. Academic Medicine 1998, 73:1133

5. Schwarz M, Wojtczak A: Global minimum essential requirements: a road towards competence-oriented medical education. Medical Teacher 2002, 24:125-129.

6. Villegas-Álvarez F, Polaco-Castillo A, González-Zamora J, García-Pineda A, Madrid-Zavala M: Competencias médico-quirúrgicas. Autopercepción en médicos recién egresados de la licenciatura. Cirugía Y Cirujanos 2007, 75:43-47.

7. Bolonha Declaration: The European Higher Education Area. Joint Declaration of the European Ministers of Education Convened in Bologna at the 19th of June 1999

8. Sall H, Ndjaye B: Higher Education in Africa: Between Perspectives Opened by the Bologna Process and the Commodification of Education. European Education 2007, 39:43-57.

9. Health Professions Council of South Africa's: Regulations Relating to the Registration of Students, Undergraduate Curricula and Professional Examinations in Medicine. Department of Health; 2002.

10. Programa das Nações Unidas para o Desenvolvimento (PNUD) em Angola: Objectivos de Desenvolvimento do Milénio. 2005.

11. Fresta M, Venturelli J, Ferreira A: A Reforma do Curso de Medicina; conclusões e recomendações do seminário inicial. Revista Angolana de Educação Médica 2004, 1:15-24.

12. Sousa F Jr, Schwalbach J, Adam Y, Gonçalves L, Ferrinho P: The training and expectations of medical students in Mozambique. Human Resources for Health 2007, 5:11.

13. Shawa L: The Bologna Process and the European Gain: Africa's Development Demise? European Education 2008, 40:97-106.

14. Jones R, Higgs R, de Angelis C, Prideaux D: Changing face of medical curricula. . The Lancet 2001, 357:699-703.

15. Centro de Estudos Avançados em Educação e Formação Médica: Avaliação Interna da Faculdade de Medicina da UAN. Revista Angolana de Educação Médica 2006.

16. Faculdade de Medicina da Universidade do Porto \& Faculdade de Medicina da Universidade Agostinho Neto: Relatório Final de Avaliação Institucional da FMUAN. Luanda; 2007.

17. Faculdade de Medicina da Universidade do Porto \& Faculdade de Medicina da Universidade Agostinho Neto: Programa Estruturante de Qualidade e Excelência da Educação/Formação Médica na FMUAN. Perfil do Médico em Angola. Universidade do Porto, Porto; 2009.
18. Victorino R, Jollie C, McKim J: Licenciado Médico em Portugal. Core Graduates Learning Outcomes Project Lisboa: Faculdade de Medicina de Lisboa 2005.

19. Tabachnick B, Fidell L: Using multivariate statistics (2007) 5th. Boston: Pearson/Allyn \& Bacon

20. Bland J, Altman D: Cronbach's alpha. BMJ: British Medical Journal 1997, 314:572.

21. Busari J, Verhagen E, Muskiet F: The influence of the cultural climate of the training environment on physicians' self-perception of competence and preparedness for practice. BMC Medical Education 2008, 8:51.

22. Hesketh E, Allan M, Harden R, Macpherson S: New doctors' perceptions of their educational development during their first year of postgraduate training. Medical Teacher 2003, 25:67-76.

23. Korszun A, Winterburn P, Sweetland H, Tapper-Jones L, Houston H: Assessment of professional attitude and conduct in medical undergraduates. Medical Teacher 2005, 27:704-708.

24. Prince K, van Eijs P, Boshuizen H, van der Vleuten C, Scherpbier A: General competencies of problem-based learning (PBL) and non-PBL graduates. Medical Education 2005, 39:394-401.

25. Maxwell S, Walley T: Teaching safe and effective prescribing in UK medical schools: a core curriculum for tomorrow's doctors. British journal of clinical pharmacology 2003, 55:496.

26. Stewart J, O'Halloran C, Barton J, Singleton S, Harrigan P, Spencer J: Clarifying the concepts of confidence and competence to produce appropriate self-evaluation measurement scales. Medical Education 2000, 34:903-909.

27. Weiss $P$, Koller $C$, Hess $L$, Wasser $T$ : How do medical student selfassessments compare with their final clerkship grades? Medical Teacher 2005, 27:445-449.

28. Holmboe ES, Hawkins RE: Methods for evaluating the clinical competence of residents in internal medicine: a review. Annals of internal Medicine 1998, 129(1):42.

\section{Pre-publication history}

The pre-publication history for this paper can be accessed here: http://www.biomedcentral.com/1472-6920/11/24/prepub

doi:10.1186/1472-6920-11-24

Cite this article as: Barbosa et al.: How students perceive medical competences: a cross-cultural study between the Medical Course in Portugal and African Portuguese Speaking Countries. BMC Medical Education 2011 11:24.

\section{Submit your next manuscript to BioMed Central and take full advantage of:}

- Convenient online submission

- Thorough peer review

- No space constraints or color figure charges

- Immediate publication on acceptance

- Inclusion in PubMed, CAS, Scopus and Google Scholar

- Research which is freely available for redistribution

Submit your manuscript at www.biomedcentral.com/submit
C Biomed Central 